\title{
CRIMES HEDIONDOS: ANÁLISE PROPEDÊUTICA E PROGRESSÃO ESPECIAL DE REGIME INSTITUÍDA PELA LEI 13.769/18
}

\author{
Fabiana Vergílio Souto
}

Bacharela em Direito pela Universidade do Oeste Paulista - UNOESTE (2017). Pós-graduada em Segurança Pública Ênfase em Atividades Policiais, Faculdade CERS (2020). E-mail: fabianavergiliosouto@hotmail.com

\section{RESUMO}

O presente estudo teve como escopo apontar conceitos propedêuticos acerca dos crimes hediondos, devidamente atualizados pela Lei 13.964/19 e demonstrar as diretrizes quanto à progressão especial de regime, estabelecidas pela Lei 13.769/18 que, dentre outras alterações, incluiu os $\S \S 3$ ㅇ e 4으 ao artigo 112 da Lei 7.210/84 (Lei de Execução Penal).

O método hipotético-dedutivo, por meio de pesquisa bibliográfica, viabiliza o estudo, visto que, qualitativamente, apresenta considerações basilares acerca dos crimes hediondos e as novas regras aplicáveis quanto à progressão de regime excepcionalmente no caso de mulher gestante ou que for mãe ou responsável por crianças ou pessoas com deficiência, apesar da superveniência da Lei 13.964/19 (Pacote Anticrime) que estabeleceu diretrizes mais rigorosas para progressão de regime. Aspira-se com inovações legislativas como as consideradas, a operação do Direito Penal como eficaz instrumento de proteção e pacificação social, em prol da dignidade humana, conjuntura axiológica esta, esboçada pela prescrição de uma pena que tenha o maior aproveitamento plausível, cumprindo as finalidades retributiva, preventiva e ressocializadora à custa de um menor sofrimento possível ao ser executada.

Palavras-chave: Lei de Crimes Hediondos. Lei 13.769/18. Lei de Execução Penal. Política criminal. Progressão especial de regime.

\section{HEINOUS CRIMES: FUNDAMENTAL ANALYSIS AND SPECIAL PENAL PROGRESSION ESTABLISHED BY LAW 13.769/18}

\begin{abstract}
The present study aimed to define proposed concepts about heinous crimes, with the minimum right allowed by Law 13.964/19 and to demonstrate how the special progression rules of the regime, applicable by Law 13.769/18, include other changes, including $\S \S 3$ and 4 to article 112 of Law 7.210 /84 (Criminal Execution Law).

The hypothetical-deductive method, by means of bibliographic research, enables the study, qualitatively, presents basic considerations about the heinous crimes and the new norms applicable to the progression of regime exceptionally in the case of pregnant women or that is mother or responsible for children or disabled people, despite the supervenience of Law 13.964/19, which established stricter guidelines on regime progression. Aspiring with legislative innovations such as using, an operation of Criminal Law as an instrument of social protection, for the benefit of human dignity, established axiological conjuncture, outlined by the prescription of a sentence that has the greatest possible use, fulfilling as retributive purposes, preventive and resocialization at the cost of the least possible suffering to be executed.
\end{abstract}

Keywords: Heinous Crimes Law. Law 13.769/18. Criminal Execution Law. Criminal policy.

Special progression of prison regime. 


\section{INTRODUÇÃO}

A presente pesquisa exploratória teve como escopo apontar conceitos propedêuticos acerca dos crimes hediondos e demonstrar concisamente as novas diretrizes quanto à progressão de regime estabelecidas pela Lei $13.769 / 18$, que deu nova redação ao artigo 2o, § 2으, da Lei 8.072/90 (Lei dos Crimes Hediondos) recentemente revogado pela Lei 13.964/19 (Pacote Anticrime) - e inclusão dos §§ 3ㅇ e 40 à Lei 7.210/84 (Lei de Execução Penal) em pleno vigor.

A sucinta análise propedêutica visa conceituar "crimes hediondos" no contexto da legislação brasileira, proporcionando aos leitores, especialmente aos leigos, conhecimento basilar acerca do tema, considerando que as inovações da Lei $13.769 / 18$ incidiram sobre dispositivos preexistentes, complementando-os, tal como se deu com a Lei de Crimes Hediondos, ou incluindo novas normas, como ocorreu com a Lei de Execução Penal.

É de notável relevância a pesquisa exploratória, posto que consiste em inovação legislativa, além de mecanismo para humanização do cumprimento de pena.

A nova diretriz visa proteger, ou de forma humanizada, conceder à mulher gestante ou que for mãe ou responsável por crianças ou pessoas com deficiência, norma mais benéfica quanto à progressão de regime.

\section{CRIMES HEDIONDOS: CONCEITUAÇÃO E SUMÁRIAS OBSERVAÇÕES HISTÓRICAS}

Não existe um conceito específico para que se possa definir crime hediondo, pois o legislador optou por definir diretamente quais crimes iriam compor a lista prevista em lei.

A Lei de Crimes Hediondos teve sua previsão na Constituição Federal de 1988, no artigo $5^{\circ}$, inciso $\mathrm{XLIII}^{1}$, competindo ao legislador a edição da lei para definir quais os crimes seriam considerados hediondos.

A ideia de hediondez no contexto do comportamento humano é de descomplicada cognição, dispensando definição. Todavia, no momento em que é instituída como qualificativo

\footnotetext{
${ }^{1}$ Art. 5o, XLIII da Constituição Federal - a lei considerará crimes inafiançáveis e insuscetíveis de graça ou anistia a prática da tortura, o tráfico ilícito de entorpecentes e drogas afins, o terrorismo e os definidos como crimes hediondos, por eles respondendo os mandantes, os executores e os que, podendo evitá-los, se omitirem. (BRASIL, 1988)
}

de um delito, considerando o princípio da reserva legal, há que se implementar, necessariamente, tipificação legal (MONTEIRO, 2015, p. 37-38).

Deste modo é que o próprio texto constitucional, no inciso aludido, determina que hediondos serão aqueles crimes definidos em lei. Trata-se do nascedouro da Lei 8.072, de 25 de julho de 1990, como resposta ao mandado constitucional de criminalização (MONTEIRO, 2015, p. 37-38).

Para possibilitar a aplicação do dispositivo legal supracitado, foram aprovadas várias leis. A mais importante foi a Lei 8.072/90, conhecida como Lei dos Crimes Hediondos, objeto de estudo da presente pesquisa, que determinou os tipos penais considerados hediondos e estipulou medidas de ordem penal e processual penal, além de deliberações quanto à execução da pena de tais delitos.

No entendimento doutrinário, Bina (2015): "São considerados hediondos os crimes cuja lesividade é acentuadamente expressiva, ou seja, crime de extremo potencial ofensivo, ao qual denominamos crime de gravidade acentuada".

Gonçalves (2017, p. 12) leciona:

Em nossa legislação, o caráter hediondo depende única e exclusivamente da existência de previsão legal reconhecendo essa natureza para determinada espécie delituosa. Com efeito, o art. 1ㅇ da Lei no 8.072/90 apresenta um rol taxativo desses crimes, não admitindo ampliação pelo juiz. Não se admite, tampouco, que o magistrado deixe de reconhecer a natureza hedionda em delito que expressamente conste do rol. Adotou-se, portanto, um critério que se baseia exclusivamente na existência de lei que confira caráter hediondo a certos ilícitos penais. Assim, por mais grave que seja determinado crime, o juiz não the poderá conferir o caráter hediondo, se tal ilícito não 
constar do rol da Lei no 8.072/90.

Dessarte, por meio de rol taxativo, serão considerados como tais, aqueles crimes expressamente previstos em lei, elencados no art. 10 da Lei de Crimes Hediondos:

Art. 1ํ. São considerados hediondos os seguintes crimes, todos tipificados no Decreto-Lei $\quad n^{\circ} 2.848$, de 7 de dezembro de 1940 - Código Penal, consumados ou tentados: I - homicídio (art. 121), quando praticado em atividade típica de grupo de extermínio, ainda que cometido por um só agente, e homicídio qualificado;

I-A - lesão corporal dolosa de natureza gravíssima (art. 129, § 2ㅇ) e lesão corporal seguida de morte (art. 129, § 3ㅇ), quando praticadas contra autoridade ou agente descrito nos arts. 142 e 144 da Constituição Federal, integrantes do sistema prisional e da Força Nacional de Segurança Pública, no exercício da função ou em decorrência dela, ou contra seu cônjuge, companheiro ou parente consanguíneo até terceiro grau, em razão dessa condição;

II - roubo:

a) circunstanciado pela restrição de liberdade da vítima (art. 157, § 20, inciso V);

b) circunstanciado pelo emprego de arma de fogo (art. 157, § 20-A, inciso I) ou pelo emprego de arma de fogo de uso proibido ou restrito (art. 157, § 2--B);

c) qualificado pelo resultado lesão corporal grave ou morte (art. 157, § 3ㅇ);

III - extorsão qualificada pela restrição da liberdade da vítima, ocorrência de lesão corporal ou morte (art. 158, § 3ㅇ); (art. 158, § 2o);

IV - extorsão mediante sequestro e na forma qualificada (art. 159 , caput, e $\S \S 10$, 2ㅇ e 3ㅇ);

$\mathrm{V}$ - estupro (art. 213, caput e $\S \S 10$ e 2ㅇ);

$\mathrm{VI}$ - estupro de vulnerável (art. 217-A, caput e $\S \S 10$, 2으, 3 으 e 4의);

VII - epidemia com resultado morte (art. 267, $\S 1$ );

VII-B - falsificação, corrupção, adulteração ou alteração de produto destinado a fins terapêuticos ou medicinais;

VIII - favorecimento da prostituição ou de outra forma de exploração sexual de criança ou adolescente ou de vulnerável (art. 218-B, caput, e $\S \S 1$ 을 e 2 o).

IX - furto qualificado pelo emprego de explosivo ou de artefato análogo que cause perigo comum (art. 155, § 4ㅇ-A).

Parágrafo único. Consideram-se também hediondos, tentados ou consumados:

I - o crime de genocídio, previsto nos arts. 1ㅇ, 2으 e 3으 da Lei $\mathrm{n}$ ㅇ 2.889, de 1 응 de outubro de 1956;

II - o crime de posse ou porte ilegal de arma de fogo de uso proibido, previsto no art. 16 da Lei no 10.826, de 22 de dezembro de 2003;

III - o crime de comércio ilegal de armas de fogo, previsto no art. 17 da Lei no 10.826 , de 22 de dezembro de 2003;

IV - o crime de tráfico internacional de arma de fogo, acessório ou munição, previsto no art. 18 da Lei no 10.826 , de 22 de dezembro de 2003; 
V - o crime de organização criminosa, quando direcionado à prática de crime hediondo ou equiparado. (BRASIL, 1990)

A mera categorização de alguns crimes como de grande potencial ofensivo em detrimento de toda a sociedade não é o suficiente para obstar suas práticas.

Os crimes equiparados não são propriamente hediondos, mas são aplicados a estes os mesmos efeitos penais e processuais penais conferidos em lei aos elencados no art. 1으 da Lei 8.072/90.

Não são classificados como crimes hediondos, mas são assemelhados a estes, segundo determinação do art. 2 o da Lei 8.072/90: a tortura (Lei 9.455/97), o terrorismo e o tráfico ilícito de entorpecentes e drogas afins (Lei 11.343/06):

Art. 2ㅇ da Lei 8.072/90 Os crimes hediondos, a prática da tortura, o tráfico ilícito de entorpecentes e drogas afins e o terrorismo são insuscetíveis de:

I - anistia, graça e indulto; II - fiança. (BRASIL, 1990)

O legislador pátrio, atento à mencionada evolução jurisprudencial, editou em 28 de março de 2007, a Lei 11.464, que, modificando a redação da Lei 8.072/90, derrogou a vedação à progressão de regime, estabelecendo que a pena a condenados por crimes hediondos, tortura, tráfico de drogas e terrorismo devem ser descontadas apenas inicialmente no regime fechado.

É conveniente a distinção entre crimes hediondos e equiparados, pois não são crimes considerados efetivamente hediondos, mas a estes são aplicados os aspectos penais e processuais penais previstos na Lei 8.072/90, recebendo o investigado, indiciado, acusado ou condenado pela prática de qualquer um dos crimes previstos nestas leis, o mesmo tratamento jurídico concedido ao autor de crime hediondo (BINA, 2015).

A lei definiu que os condenados aos crimes supramencionados cumprissem a pena inicialmente em regime fechado. ${ }^{2}$ Entretanto, o STF, no julgamento do HC 111.840-ES em 14 de junho 2012, revelou a inconstitucionalidade da obrigatoriedade do regime inicialmente fechado devido à violação da cláusula de reserva jurisdicional. Somente o juiz competente para processar e julgar pode estabelecer em sede de sentença penal condenatória fundamentada o regime inicial de pena de um réu condenado.

Habeas corpus. Penal. Tráfico de entorpecentes. Crime praticado durante a vigência da Lei $\mathrm{n}$ 은 11.464/07. Pena inferior a 8 anos de reclusão. Obrigatoriedade de imposição do regime inicial fechado. Declaração incidental de inconstitucionalidade do $\S$ 1ㅇ do art. 2ㅇ da Lei no $8.072 / 90$. Ofensa à garantia constitucional da individualização da pena (inciso XLVI do art. 5o da

$\mathrm{CF} / 88)$. Fundamentação necessária $(C P$, art. $33, \S$ 3o, c/c o art. 59). Possibilidade de fixação, no caso em exame, do regime semiaberto para o início de cumprimento da pena privativa de liberdade. Ordem concedida (BRASIL, 2012, p. 1).

Do aludido julgado, enfatiza-se:

[...] persistiu - e ainda persiste - a ofensa ao princípio da individualização pena. Ora, se 0 dispositivo responsável por impor o integral cumprimento da reprimenda no regime fechado é inconstitucional, também o é aquele que determina a todos independentemente da pena a ser descontada ou

\footnotetext{
2 É inconstitucional a fixação ex lege, com base no art. 2o, § 1으, da Lei 8.072/1990, do regime inicial fechado, devendo o julgador, quando da condenação, ater-se aos parâmetros previstos no artigo 33 do Código Penal.

(Cf. Tese definida no ARE 1.052.700 RG, rel. min. Edson Fachin, $\mathrm{P}, \mathrm{j}$ 2-11-2017, DJE 18 de 10-2-2018, Tema 972).
} 
das nuances do caso a caso - que iniciem a expiação no regime mais gravoso (BRASIL, 2012, p. 13).

Verifica-se que a lei não estava em consonância com o princípio da proporcionalidade, considerando que a imposição do regime fechado até mesmo a condenados a penas ínfimas, primários e de bons antecedentes, entrava em conflito valorativo com a Constituição e com a humanização do Direito Penal.

Consoante à disposição exordial da Lei 8.072/90, aqueles condenados por crimes hediondos ou equiparados deveriam cumprir a pena integralmente em regime fechado, ausente a progressão para os regimes semiaberto e aberto.

O impedimento da progressão de

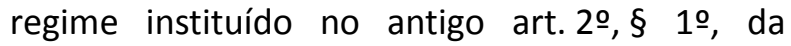
Lei 8.072/90, depreciou o basilar princípio da dignidade da pessoa humana, ao imputar pena cruel ao sentenciado.

De acordo com Gonçalves (2018, p. 66): "[...] o Supremo Tribunal Federal, no julgamento do HC 82.959, em 23 de fevereiro de 2006, decidiu que essa regra era inconstitucional por ferir os princípios da individualização da pena e da dignidade humana".

Tangente à progressão de regime, nos mesmos termos proferidos no HC 82.959/SP:

A progressão no regime de cumprimento da pena, nas espécies fechado, semiaberto e aberto, tem como razão maior a ressocialização do preso que, mais dia ou menos dia, voltará ao convívio social (...). Conflita com a garantia da individualização da pena artigo 5o, inciso XLVI, da Constituição Federal - a imposição, mediante norma, do cumprimento da pena em regime integralmente fechado. Nova inteligência do princípio da individualização da pena, em evolução jurisprudencial, assentada a inconstitucionalidade do artigo 2으, § 1으, da Lei $\mathrm{n}$ 8.072/90 (BRASIL, 1990).

Tendo em consideração o princípio da individualização da pena:

[...] a pena é individualizada porque o Estado-Juiz, ao fixá-la, está compelido, por norma cogente, a observar as circunstâncias judiciais, ou seja, os fatos objetivos e subjetivos que se fizeram presentes à época do procedimento criminalmente condenável. Ela o é não em relação ao crime considerado

abstratamente, ou seja, ao tipo definido em lei, mas por força das circunstâncias reinantes à época da prática. Daí cogitar o artigo 59 do Código Penal que o juiz, atendendo culpabilidade, aos antecedentes, à conduta social, a personalidade do agente, aos motivos, às circunstâncias

consequências do crime, bem como ao comportamento da vítima, estabelecerá, conforme seja necessário e suficiente para reprovação e prevenção do crime, não só as penas aplicáveis dentre as cominadas (inciso I), como também o quantitativo (inciso II), o regime inicial de cumprimento da pena privativa de liberdade - e, portanto, provisório, já que passível de modificação até mesmo para adotar-se regime mais rigoroso (inciso III) - e a substituição da pena privativa da liberdade aplicada, por outra espécie de pena, se cabível (BRASIL, 2006, p. 516).

[...] a progressividade do regime está 
umbilicalmente ligada à própria pena, no que, acenando ao condenado com dias melhores, incentiva-o à correção de rumo e, portanto, a empreender um comportamento penitenciário voltado à ordem, ao mérito e a uma futura inserção social (BRASIL, 2006).

Disso decorreu a alteração dada pela Lei 11.464/07, normatizando a progressão de regime de cumprimento da pena privativa de liberdade para os crimes hediondos.

$\mathrm{Na}$ generalidade, um indivíduo condenado por crime não hediondo ou equiparado a hediondo, poderia progredir de regime mais gravoso para outro mais brando mediante cumprimento de um sexto da pena e comprovação de bom comportamento. Contudo, a Lei de Crimes Hediondos estipulou regra diferente, de modo que a progressão de regime ocorreria após o cumprimento de $2 / 5$ (dois quintos) da pena, sendo o apenado primário, e de $3 / 5$ (três quintos), se reincidente (BINA, 2015).

Todavia, com a entrada em vigor da Lei 13.964/19 (Pacote Anticrime), têm-se novas disposições para a progressão de regime:

Art. 112. A pena privativa
de liberdade será
executada em forma
progressiva com a
transferência para regime
menos rigoroso, a ser
determinada pelo juiz,
quando o preso tiver
cumprido ao menos:
I - 16\% (dezesseis por
cento) da pena, se o
apenado for primário e o
crime tiver sido cometido
sem violência à pessoa ou
grave ameaça;
II - 20\% (vinte por cento)
da pena, se o apenado for
reincidente em crime
cometido sem violência à
pessoa ou grave ameaça;
III - 25\% (vinte e cinco por
cento) da pena, se o
apenado for primário e o
crime tiver sido cometido
com violência à pessoa ou
grave ameaça;

IV - 30\% (trinta por cento) da pena, se o apenado for reincidente em crime cometido com violência à pessoa ou grave ameaça; $\mathrm{V}$ - $40 \%$ (quarenta por cento) da pena, se o apenado for condenado pela prática de crime hediondo ou equiparado, se for primário;

VI - 50\% (cinquenta por cento) da pena, se o apenado for:

a) condenado pela prática de crime hediondo ou equiparado, com resultado morte, se for primário, vedado o livramento condicional;

b) condenado por exercer o comando, individual ou coletivo, de organização criminosa estruturada para a prática de crime hediondo ou equiparado; ou

c) condenado pela prática do crime de constituição de milícia privada;

VII - 60\% (sessenta por cento) da pena, se o apenado for reincidente na prática de crime hediondo ou equiparado;

VIII - 70\% (setenta por cento) da pena, se o apenado for reincidente em crime hediondo ou equiparado com resultado morte, vedado o livramento condicional.

\section{PROGRESSÃO DE REGIME ESPECIAL NO CASO DE MULHER GESTANTE OU QUE FOR MÃE OU RESPONSÁVEL POR CRIANÇAS OU PESSOAS COM DEFICIÊNCIA}

Publicada a Lei $13.769 / 18$, passou-se a exigir a observância dos §§ 3ㅇ e 4으 do artigo 112 da Lei de Execução Penal, que concedem uma espécie de benesse quanto à progressão de regime.

Trata-se de uma inovação prevista tãosomente para mulher gestante ou que for mãe ou responsável por crianças ou pessoas com deficiência. Cabe destacar que os requisitos devem ser verificados cumulativamente, ipsis litteris: 
$\S 3$ ㅇ No caso de mulher gestante ou que for mãe ou responsável por crianças ou pessoas com deficiência, os requisitos para progressão de regime são, cumulativamente:

I - não ter cometido crime com violência ou grave ameaça à pessoa;

II - não ter cometido o crime contra seu filho ou dependente;

III - ter cumprido ao menos $1 / 8$ (um oitavo) da pena no regime anterior;

IV - ser primária e ter bom comportamento

carcerário, comprovado pelo diretor do estabelecimento;

$\mathrm{V}$ - não ter integrado organização criminosa.

$\S$ 4으 O cometimento de novo crime doloso ou falta grave implicará a revogação do benefício previsto no $\S$ 3ㅇ deste artigo. (BRASIL, 1984)

O requisito disposto no inciso I restringe esta modalidade de aplicação da progressão de regime, de modo que as apenadas que cumprem pena por crime cometido com violência ou grave ameaça à pessoa, não serão beneficiadas.

O inciso II veda esse modelo de progressão na hipótese de o crime ser perpetrado contra filho ou dependente, visto que essa benesse é destinada tanto à mulher apenada, quanto àquele que depende de seus cuidados, seja filho ou dependente.

Atinente ao inciso III há a previsão de prazo distinto para a progressão de regime, admissível apenas na referida hipótese, sendo o cumprimento de $1 / 8$ da pena no regime atual conditio sine qua non para a aplicação do benefício humanitário.

A primeira parte do inciso IV estipula como requisito ser primária, excluindo aquelas reincidentes $^{3}$ na concessão do privilégio. A segunda parte do inciso apresenta a exigência de bom comportamento carcerário, comprovado

\footnotetext{
${ }^{3}$ Art. 63 do Código Penal - Verifica-se a reincidência quando o agente comete novo crime, depois de transitar em julgado a sentença que, no País ou no estrangeiro, o tenha condenado por crime anterior.
}

mediante atestado de conduta assinado pelo diretor do estabelecimento prisional.

Deste modo, se a apenada está enquadrada na primariedade penal exigida no inciso IV - além de cumprir os demais requisitos deverá ser aplicado o benefício especial de progressão.

$\mathrm{O}$ último requisito, disposto no inciso $\mathrm{V}$, preceitua que a apenada não tenha integrado organização criminosa.

No que diz respeito ao $\S 40$, ocorrendo a prática de novo crime doloso ou falta grave, acarretará a revogação do benefício previsto no artigo precedente.

Ademais, a Lei $13.769 / 18$ incluiu o inciso VII ao art. 72 da Lei de Execução Penal, conferindo ao Departamento Penitenciário Nacional a incumbência de "acompanhar a execução da pena das mulheres beneficiadas pela progressão especial de que trata o § 30 do art. 112 desta Lei, monitorando sua integração social e a ocorrência de reincidência, específica ou não, mediante a realização de avaliações periódicas e de estatísticas criminais".

Evidentemente que o legislador, no processo de nomogênese, considerou os clamores sociais quanto às mazelas típicas do sistema penitenciário pátrio, e as constantes violações de preceitos fundamentais, como a dignidade da pessoa humana, impulsionaram o legislativo. Cabe citar Souto (2018, p. 8-9): “[...] na nomogênese jurídica, o nascedouro legal, há que se falar nas forças sociais que atuam fortemente sobre a legislação, impulsionando a criação das normas em prol do bem comum, finalidade última do Estado".

\section{CONCLUSÃO}

Portanto, às apenadas que satisfaçam cumulativamente os requisitos dispostos no $\S 3$ 은 do artigo 112 da Lei de Execuções Penais, inclusive nos casos de crime hediondo ou equiparado (desde que não tenha sido praticado com violência ou grave ameaça à pessoa), dar-seá a progressão para regime mais brando considerando o cumprimento de $1 / 8$ da pena no regime prisional anterior.

Por meio da presente pesquisa, constata-se que as novas disposições para concessão de progressão especial de regime constitui política criminal de ampla aplicação prática e de enaltecimento humanitário, instrumento de humanização da pena ante as limitações e condições precárias do sistema 
penitenciário brasileiro, beneficiando não apenas a mulher gestante ou que for mãe ou responsável por crianças ou pessoas com deficiência, mas, sobretudo, aquele que depende de seus cuidados.

Logra-se com isso a aplicação do Direito Penal como eficaz instrumento de proteção e pacificação social, culminando naturalmente no enaltecimento do princípio da humanidade, conjuntura axiológica esta, manifestada pela prescrição de uma pena que tenha o maior aproveitamento plausível, cumprindo a finalidade retributiva, preventiva e ressocializadora à custa de um menor sofrimento possível ao ser executada.

\section{REFERÊNCIAS}

BINA, Ricardo Ambrósio Fazzani. Série Universitária - Legislação Penal Especial. 1. ed. Rio de Janeiro: Elsevier, 2015.

BRASIL. Constituição (1988). Constituição da República Federativa do Brasil. Brasília, DF: Senado Federal, 1988. Disponível em: http://www.planalto.gov.br/ccivil_03/constituica o/constituicaocompilado.htm. Acesso em 16 mar. 2020.

BRASIL. Presidência da República. Lei no 13.769, de 19 de dezembro de 2018. Altera o Decreto-Lei no 3.689, de 3 de outubro de 1941 (Código de Processo Penal), as Leis $\mathrm{n} \cong 7.210$, de 11 de julho de 1984 (Lei de Execução Penal), e 8.072, de 25 de julho de 1990 (Lei dos Crimes Hediondos), para estabelecer a substituição da prisão preventiva por prisão domiciliar da mulher gestante ou que for mãe ou responsável por crianças ou pessoas com deficiência e para disciplinar o regime de cumprimento de pena privativa de liberdade de condenadas na mesma situação. Brasília, 2018. Disponível em: http://www.planalto.gov.br/ccivil_03/_ato20152018/2018/lei/L13769.htm. Acesso em: 15 mar. 2020.

BRASIL. Presidência da República. Lei no 8.072, de 25 de julho de 1990. Lei dos Crimes Hediondos. Dispõe sobre os crimes hediondos, nos termos do art. 5ㅇ, inciso XLIII, da Constituição Federal, e determina outras providências. Brasília, $1990 . \quad$ Disponível em: http://www.planalto.gov.br/ccivil_03/Leis/L8072. htm. Acesso em: 16 de mar. 2020.
BRASIL. Presidência da República. Lei no 7.210, de 11 de julho de 1984. Lei de Execução Penal. Brasília, $1984 . \quad$ Disponível em: http://www.planalto.gov.br/ccivil_03/leis/17210. htm. Acesso em: 16 mar. 2020.

BRASIL. Supremo Tribunal Federal. Habeas Corpus n. 82.959/SP, Impetrante(s): Oseas de Campos. Relator Min. Marco Aurélio. São Paulo, 23 fev, $2006 . \quad$ Disponível em: http://redir.stf.jus.br/paginadorpub/paginador.js $p$ ?docTP=AC\&doc $I D=79206$. Acesso em: 16 de mar. 2020.

BRASIL. Supremo Tribunal Federal. Habeas Corpus n. 111.840/ES, Impetrante: Defensoria Pública do Estado do Espírito Santo. Relator Min. Dias Toffoli. Espírito Santo, 14 jun. 2012. Disponível em: http://www.stf.jus.br/arquivo/cms/noticianoticia stf/anexo/hc111840dt.pdf. Acesso em: 16 mar. 2020.

GONÇALVES, Victor Rios. Legislação penal especial: crimes hediondos - drogas - terrorismo - tortura - armas de fogo - contravenções penais - crimes de trânsito. 14. ed. São Paulo: Saraiva, 2017.

MONTEIRO, Antônio Lopes. Crimes Hediondos: texto, comentários e aspectos polêmicos. 10. ed. São Paulo: Saraiva, 2015.

SOUTO, Fabiana Vergílio. Breves apontamentos sobre a incidência valorativa na nomogênese e subsunção. Colloquium Socialis, Presidente Prudente, v. 2, n. 1, p. 06-12, dez. 2018. https://doi.org/10.5747/cs.2018.v02.n1.s022 